\title{
DAS DIRETRIZES NACIONAIS ÀS ORIENTAÇÕES LOCAIS NA EDUCAÇÃO EM DIREITOS HUMANOS - 0 caso da escola integrada de Belo Horizonte 1
}

\author{
Patricia dos Santos Dias Viana \\ Centro Universitário UNA \\ Maria Lucia Miranda Afonso \\ Centro Universitário UNA
}

\begin{abstract}
Resumo
Este artigo objetiva analisar a relação entre as diretrizes nacionais para educação em direitos humanos e as diretrizes construídas em nível local, no caso, no município de Belo Horizonte. Intenciona contribuir para o campo das Educação em Direitos Humanos (EDH) por meio da problematização da sua aplicação no campo da educação em diferentes esferas políticas. A metodologia utilizada foi a análise documental. Foram estudados e comparados os documentos legais sobre a EAD na esfera federal e na esfera municipal, com atenção aos princípios, valores e proposição de ações. Os resultados mostraram denota que o município de Belo Horizonte aderiu à proposta federal e lhe imprimiu uma importância grande. Porém, em nível local, o desenvolvimento da EAD foi incorporado e articulado com outros planos educacionais, como o Programa Escola Integrada, adquirindo uma feição própria. Constatou-se a importância e preocupação com a EDH para o desenvolvimento e formação cidadã das crianças e adolescentes e seus impactos na comunidade local.
\end{abstract}

Palavras-chave: Educação em Direitos Humanos. Escola Integrada. Desenvolvimento local. Cidadania.

\begin{abstract}
This article aims to analyze the relationship between the national guidelines for human rights education and the guidelines built at the local level, in this case, in the city of Belo Horizonte. It intends to contribute to the field of Education in Human Rights (EDH) by questioning its application in the field of education in different political spheres. The methodology used was document analysis. Legal documents about EDH were studied and compared at the federal and municipal levels, with attention to the principles, values and proposition for actions. The results showed that the municipality of Belo Horizonte has adhered to the federal proposal and gave it great importance. However, at the local level, the development of EDH was incorporated and articulated with other educational plans, such as the Integrated School, taking on a characteristic of its own. The results also demonstrated the importance and concern with $\mathrm{EDH}$ for the development and citizen formation of children and adolescents and their impacts on the local community.
\end{abstract}

Keywords: Education in Human Rights. Integrated Education. Local Development. Citizenship. 


\section{Introdução}

Este artigo apresenta uma pesquisa realizada sobre o processo existente na captação das diretrizes nacionais em nível municipal, no caso da Educação em Direitos Humanos (EDH). Busca-se contribuir para a compreensão da efetivação da EDH a partir de planos e diretrizes nacionais analisando como podem ser retraduzidas e apropriadas nas municipalidades, o que pode fortalecer ou enfraquecer as propostas iniciais, certamente a elas imprimindo uma feição própria. Ao mesmo tempo, essa apropriação municipal deve ser valorizada pois indica o movimento dinâmico da gestão pública e da expressão da realidade local. Em Belo Horizonte, a EDH foi integrada ao programa municipal de Educação Integrada.

Assim, o objetivo geral da pesquisa foi analisar a relação entre a proposta das diretrizes nacionais para a Educação em Direitos Humanos e as Diretrizes Político-Pedagógicas da Educação Integrada em Belo Horizonte, restringindo-se ao ensino fundamental. Como objetivos específicos, a pesquisa se propôs a comparar as diretrizes para educação em Direitos Humanos no ensino fundamental, nos documentos nacionais e nos documentos do Programa Escola Integrada da Prefeitura Municipal de Belo Horizonte, buscando perceber a sua construção específica e o sentido que atribuem à EDH. Para sua realização, a metodologia adotada foi a análise de documentos, de cunho qualitativo.

Foi feita uma revisão de literatura de documentos oficiais que discutem e orientam a Educação em Direitos Humanos, no Brasil, após a Constituição Federal de 1988. A análise abrange o período entre a Constituição Federal de 1988 (CF/88) até o ano de 2018, período em que foram incentivadas muitas propostas na educação brasileira. Essa posição foi especialmente influenciada pelos documentos internacionais dos quais o Brasil foi signatário, como o Plano Mundial de Educação em Direitos Humanos (UNESCO, 2006).

A escolha da cidade de Belo Horizonte se deu pelas iniciativas progressistas que o município encampou, na área da educação, principalmente a partir dos anos 90, com a Constituição Federal de 1988, tendo sido uma das primeiras cidades do país a implantar o Programa da Escola Integrada na década de 2000. Além disso, uma das autoras deste artigo atuou como docente no ensino fundamental municipal, problematizando questões que se transformaram em um projeto de mestrado.

Inicialmente, o artigo oferece uma compreensão sobre os Direitos Humanos e sobre a Educação em Direitos Humanos como fundamentais à promoção e à defesa da cidadania. Nessa direção, sistematiza também sobre como a EDH é expressa nos documentos nacionais. Em seguida, aborda a Política Nacional de Educação e a EDH, buscando abrir espaço para compreender a presença da EDH os Projetos Mais Educação e o Projeto Escola Integrada. O propósito foi compreender como os planos municipais se apoiam ou se afastam dos conceitos inicialmente desenvolvidos para tornar a educação em direitos humanos uma realidade em nível local e como esta, por sua vez, se manifesta, criando as suas ações. 


\section{Direitos Humanos: uma compreensão que nos leva à necessidade da educação para a cidadania e os direitos humanos}

Neste item, busca-se compreender conceitos essenciais do campo dos Direitos Humanos para a promoção da Educação em Direitos Humanos, e daí, há a abordagem da sua incorporação no município de Belo Horizonte. A educação como elemento de formação cidadã, influencia o desenvolvimento e a formação da criança e do adolescente, motivando também a participação de outros atores sociais na comunidade escolar e local.

A Educação em Direitos Humanos requer problematizar a realidade das escolas, seus educandos, familiares e comunidade, visando atividades educativas que apresentem, discutam e promovam os Direitos Humanos, ainda que existam desigualdades sociais, culturais e econômicas no contexto educativo e social (BARCELOS; AFONSO 2015, p. 110).

Resultado de grandes eventos e lutas na história mundial, falar de Direitos Humanos nos remete à Declaração Universal de Direitos Humanos (DUDH), de 1948, proclamada como um:

(...) ideal comum a atingir por todos os povos e todas as nações, a fim de que todos os indivíduos e todos os órgãos da sociedade, tendo-a constantemente no espírito, se esforcem, pelo ensino e pela educação, por desenvolver o respeito desses direitos e liberdades e por promover, por medidas progressivas de ordem nacional e internacional, o seu reconhecimento e a sua aplicação universais e efetivas tanto entre as populações dos próprios Estados - membros como entre os povos dos territórios colocados sob a sua jurisdição (ONU, 1948, p. 1).

No entender de Flávia Piovesan (2004), a DUDH foi resposta à intolerância étnica e racial no final dos anos 1930 e ao longo dos anos 1940, principalmente na Europa, e trouxe uma concepção contemporânea de direitos humanos, marcada pela universalidade e indivisibilidade desses direitos:

Universalidade porque clama pela extensão universal dos direitos humanos, com a crença de que a condição de pessoa é o requisito único para a titularidade de direitos, considerando o ser humano como essencialmente moral, dotado de unicidade existencial e dignidade. Indivisibilidade porque, ineditamente, o catálogo dos direitos civis e políticos é conjugado ao catálogo dos direitos econômicos, sociais e culturais (PIOVESAN, 2004, p. 44-45).

Neste sentido, os direitos humanos são compostos pelo conjunto dos direitos civis, políticos, sociais, econômicos e culturais que têm como característica a universalidade porque estão além das fronteiras geopolíticas, sem qualquer distinção de etnia, nacionalidade, sexo, classe social, nível de instrução, religião, opinião política, orientação sexual ou de qualquer tipo de julgamento moral, pois dizem respeito à dignidade da natureza humana. Os direitos humanos existem antes de qualquer lei e não precisam estar nela especificados para 
sua efetivação, portanto, vão além da historicidade, pois mudam ao longo do tempo num mesmo país e são reconhecidos de forma diferente em países distintos. Para os direitos humanos, não há indivisibilidade e interdependência, sporque não podem ser fracionados; nem considerados cumpridos, se separados (PIOVESAN, 2004, p. 3).

Portanto, a DUDH foi um instrumento para consolidar muitos acordos e pactos internacionais em que os estados se comprometiam a garantir direitos, justiça, paz e democracia. Além de base para a composição das normativas internas dos países.

Os DH relacionados com a garantia do princípio da dignidade humana dependem da consolidação do cidadão enquanto participante ativo das transformações sociais. Correlaciona, assim, a cidadania e os direitos humanos. O significado da cidadania encontrase com a história dos direitos humanos, a história das lutas pela afirmação de valores éticos, como a liberdade, a dignidade e a igualdade de todos os humanos (COSTA; NOVAIS, 2011, p. 4).

Os Direitos de Cidadania - DC, segundo Schiefer (2004, p.2), são entendidos como aqueles inscritos na Constituição Federal e demais preceitos do ordenamento jurídico. Para que os DC se tornem efetivos, o Estado deve garanti-los por meio de políticas públicas e outras formas de ação na sociedade. Dessa forma, os DH ganham materialidade com os DC e a própria visão de cidadania se expande e se fortalece.

Segundo Benevides (2004, p. 48), os direitos de cidadania são específicos do Estado e de uma ordem jurídica, podendo coincidir com os $\mathrm{DH}$ por estes serem mais amplos e abrangentes. E, em sociedades democráticas, os direitos e deveres do cidadão não podem ser invocados para justificar a violação dos Direitos Humanos. Neste sentido, reflete-se a cidadania como o "direito de pertencer a uma comunidade política" que permite o acesso aos direitos humanos (ARENDT apud LAFER, 1997, p. 58), mas que para isso é imprescindível uma cidadania ativa, ou seja, a participação dos cidadãos nas diversas áreas da sociedade.

A Constituição Cidadã, assim denominada a Constituição de 1988, tem como princípio os DH e, de forma sistêmica, o Estado, um conjunto de leis e políticas públicas centradas na proteção e promoção dos Direitos Humanos, objetivando em muitas ocasiões às demandas de diferentes movimentos sociais (CANDAU, SACAVINO, 2017, p. 60).

No Brasil, umas das exigências normativas é tratar os Direitos Humanos através da educação, buscando uma formação mais humanizada das pessoas e o fortalecimento dos regimes políticos democráticos na sociedade, promovendo a participação dos cidadãos. A educação é reconhecida como um dos Direitos Humanos, constando na Declaração Universal dos Direitos Humanos (ONU, 1948), que diz que toda pessoa tem direito à educação. Assim, na presente reflexão, compreende-se que a educação é parte fundamental do conjunto desses direitos, inclusive do próprio direito à educação, vista como um instrumento para a realização e efetivação dos direitos humanos com a participação dos cidadãos através da Educação em Direitos Humanos - EDH. 


\subsection{A Educação em Direitos Humanos: a formulação nos documentos nacionais}

A educação pode ser considerada uma conquista social. Mais que isso: o direito à educação é um dos principais direitos sociais. Entende-se, aqui, uma educação direcionada ao desenvolvimento integral da personalidade humana e ao fortalecimento do respeito na construção de uma sociedade ética, justa e participativa.

A Declaração Universal dos Direitos Humanos estabelece a educação como um direito humano universal, assim como o direito à vida, à segurança, à paz, à saúde e ao bem-estar, assim como os direitos humanos são concebidos como princípio e conteúdo do direito à educação:

A educação deve visar à plena expansão da personalidade humana e ao reforço dos direitos do Homem e das liberdades fundamentais e deve favorecer a compreensão, a tolerância e a amizade entre todas as nações e todos os grupos raciais ou religiosos, bem como o desenvolvimento das atividades das Nações Unidas para a manutenção da paz (ONU, 1948, Art. 26).

O item 2 do artigo 26 da DUDH, pautado nos princípios da dignidade humana, acrescenta que não basta ter direito à educação, mas é importante oferecer uma educação que amplie a humanidade das pessoas e reforce o reconhecimento dos direitos e do seu exercício, e que toda pessoa tem direito ao reconhecimento de sua dignidade como sujeito de direitos. Visando a uma educação que permita a formação e desenvolvimento de um indivíduo autônomo e crítico, Candau (2012), afirma:

(...) A educação escolar não pode ser reduzida a um produto que se negocia na lógica do mercado; nem ter como referência quase que exclusivamente a aquisição de determinados "conteúdos", por mais socialmente reconhecidos que sejam. Deve ter como horizonte a construção de uma cidadania participativa, a formação de sujeitos de direito, o desenvolvimento da vocação humana de todas as pessoas nela implicadas (CANDAU, 2012, p. 721).

Fernandes e Candau (2017, p.4) e Andrade (2008, p.55) corroboram com tal entendimento sobre o contínuo processo de formação, dizendo:

Na verdade, só somos verdadeiramente humanos se passarmos por um processo educativo. Ninguém nasce pronto e acabado como ser humano. Ao contrário, tornamo-nos humanos por um processo que chamamos de educação e ao qual temos o direito humano básico de vivenciá-lo (ANDRADE, 2008, p. 55, apud FERNANDES; CANDAU, 2017, p.4).

A educação em direitos humanos (EDH) pode ser definida como um conjunto de atividades de educação, de capacitação e de difusão de informação, fundamental para a criação de uma cultura universal de direitos humanos (UNESCO, 2006, p. 6) que, de acordo 
com Candau (2012, p.721), deve ser uma educação comprometida com a formação de sujeitos de direito e a afirmação da democracia, da justiça e do reconhecimento da diversidade, com os valores da tolerância, da solidariedade e da justiça social, com a sustentabilidade, a inclusão e a pluralidade.

O Manual Operacional de Educação Integral (BRASIL, 2012, p. 16) traz a seguinte definição de EDH:

(...) compreende um conjunto de atividades educacionais que tem a finalidade de promover o respeito dos direitos e liberdades fundamentais, contribuindo para a prevenção e combate ao preconceito, discriminação e violências. Essas atividades devem proporcionar conhecimento, habilidades, competências e empoderamento para que os estudantes sejam protagonistas da construção e promoção de uma cultura de direitos humanos.

A EDH tem por finalidade atuar na formação da pessoa em todas as suas dimensões a fim de contribuir com o desenvolvimento de sua condição de cidadão, ativo na luta por seus direitos, no cumprimento de seus deveres e na fomentação de sua humanidade. Dessa forma, torna-se capaz de atuar frente às injustiças e desigualdades, reconhecendo-se como sujeito autônomo e reconhecendo os outros com iguais direitos, dentro dos preceitos de diversidade e tolerância, valorizando assim a convivência harmoniosa, o respeito mútuo e a solidariedade (TAVARES, 2007, p.487).

Candau (2012, p. 724) afirma que educar não se restringe a ensinar conteúdos ou a só explorar competências cognitivas, mas deve, sim, ter como seus objetivos a formação de sujeitos de direitos e o desenvolvimento da vocação humana. As pessoas só se tornarão verdadeiramente cidadãs quando exercitarem seus direitos de forma ativa e participativa. Daí a concepção de cidadania ativa que não insere apenas o voto, mas a participação social, exigindo a efetivação de seus direitos civis, políticos e sociais (FERNANDES; CANDAU, 2017, p.4).

Saviani (2013, p. 745), numa perspectiva democrática, afirma sobre o sentido de educar para a cidadania, quando:

Com efeito, a educação, para além de se constituir em determinado tipo de direito, o direito social, configura-se se como condição necessária, ainda que não suficiente, para o exercício de todos os direitos, sejam eles civis, políticos, sociais, econômicos ou de qualquer outra natureza.

Ora, se analisarmos o significado da EDH, compreenderemos que é necessário que ela ocupe um lugar central no ensino e na educação, planejando-a como uma temática interdisciplinar e transversal, fundamentada numa teoria educacional, apoiando-a com as novas tecnologias e avaliando suas práticas. Consoante a isso, a educação em Direitos Humanos se assenta na tríade: conhecer e defender seus direitos; respeitar a igualdade de direitos dos outros; e estar tão comprometido quanto possível com a defesa da educação em Direitos Humanos dos outros. Supõe-se, assim, que na comunicação de saberes e valores se 
desenvolve uma compreensão das dimensões jurídica e política, assim como um bem moral e preventivo dos Direitos Humanos (CANDAU; SACAVINO, 2013, p. 61).

Nessa perspectiva da EDH é importante que os sujeitos sejam envolvidos nas histórias de conquistas dos DH, uma vez que a participação influencia a mudança social, identificando que a EDH não se reduz a alguns temas do currículo educação, mas levanta questões como a articulação entre igualdade e diferença. Neste sentido, a escola tem um papel fundamental nesta articulação com os alunos, extensivo à sua família e outros atores que compõem a comunidade onde a escola está inserida.

Educar em direitos humanos potencializa nas pessoas o respeito ao ser humano e à sua dignidade, aos valores democráticos, à tolerância e à convivência dentro das regras do estado de direito, sendo capaz de contribuir para que as pessoas assumam o papel de protagonistas de sua história, conscientes de suas responsabilidades sociais, políticas e culturais como artífices das transformações necessárias a cada realidade.

Portanto, integrar a prática dos direitos humanos ao âmbito da educação sistemática tem como finalidade alcançar maciçamente a população de todas as faixas etárias e em todas as áreas de formação. A escola e cada um de seus agentes não podem eximir-se do seu papel formador de princípios e valores, que igualmente estão ligados aos direitos humanos, pois, no cotidiano de suas ações, transmitem mais do que os conteúdos (SILVA; TAVARES, 2013, p.53).

De acordo com o Plano de Ação do Programa Mundial para Educação em Direitos Humanos (UNESCO, 2006, p.6), uma educação integral em DH não somente proporciona conhecimentos sobre os direitos humanos e os mecanismos para protegê-los, mas, transmite as aptidões necessárias para refletir, promover, defender e aplicá-los na vida cotidiana das pessoas. Para isso, deve-se partir de temáticas significativas do ponto de vista da cidadania, propiciando condições para que os sujeitos desenvolvam sua capacidade dialógica, tomem consciência de seus próprios sentimentos e emoções e desenvolvam a capacidade autônoma de tomada de decisão em situações conflitantes do ponto de vista ético/moral.

A Constituição Federal de 1988 reconhece a importância da educação ao tornar explícito em seu Artigo $6^{\circ}$ que a Educação é um direito social. Por sua vez, o artigo 205 determina uma responsabilidade compartilhada entre o Estado e a família no sentido de garantir o pleno exercício desse direito. O texto constitucional considera que a Educação deve ser "promovida e incentivada com a colaboração da sociedade, visando o pleno desenvolvimento da pessoa, seu preparo para o exercício da cidadania e sua qualificação para o trabalho".

\subsection{Plano Nacional de Educação em Direitos Humanos e as Diretrizes da Educação em Direitos Humanos}

O Plano Nacional de Educação em Direitos Humanos (PNEDH) é entendido como o reconhecimento de uma construção histórica da sociedade civil organizada, qual seja, a luta pela efetiva realização dos direitos humanos. O documento estabelece concepções, princípios, objetivos, diretrizes e linhas de ação referentes a grandes eixos de atuação, dentre os quais a Educação Básica. O PNEDH estabelece que a educação em direitos humanos deve 
ser um dos eixos fundamentais da educação básica a permear o currículo, a formação inicial e continuada dos profissionais da educação, o projeto político-pedagógico da escola, os materiais didático-pedagógicos, o modelo de gestão e a avaliação (BRASIL, 2007, p. 32).

O PNEDH se destaca enquanto política pública em dois sentidos principais: primeiro, consolidando uma proposta de um projeto de sociedade baseada nos princípios da democracia, cidadania e justiça social; segundo, reforçando um instrumento de construção de uma cultura de direitos humanos, entendida como um processo a ser aprendido e vivenciado na perspectiva da cidadania ativa.

O PNEDH tem seus objetivos e suas linhas de ação em cinco eixos: (1) educação básica; (2) educação superior; (3) educação não formal; (4) educação dos profissionais dos sistemas de justiça e segurança; e (5) educação e mídia.

Para o PNEDH é fundamental que a EDH proporcione uma reflexão sobre valores, atitudes e práticas sociais relacionados à cultura dos direitos humanos, como base para uma consciência cidadã. Além disso, sugere a adoção de processos metodológicos participativos, de construção coletiva, com linguagens e materiais didáticos que promovam os valores, as atitudes, as ações, as estratégias e os instrumentos em favor da defesa, da promoção e da ampliação dos direitos humanos (AFONSO; ABADE, 2013).

Assim, através de programas que a escola expande seu ambiente, além de um espaço de experimentar a cultura dos direitos humanos, procura efetivar as políticas da EDH, tendo os professores e outros agentes como promotores desse ambiente, conduzindo a relação com os alunos, com a escola, com a comunidade e com o conhecimento - uma vivência democrática norteada pela experiência cotidiana dos direitos humanos (ARAÚJO; AFONSO, 2018).

Como referência, o PNEDH evidencia os seguintes princípios para a Educação Básica: a) a educação deve ter a função de desenvolver uma cultura de direitos humanos em todos os espaços sociais; b) a escola, como espaço privilegiado para a construção e consolidação da cultura de direitos humanos, deve assegurar que os objetivos e as práticas a serem adotados sejam coerentes com os valores e princípios da educação em direitos humanos; c) a educação em direitos humanos, por seu caráter coletivo, democrático e participativo, deve ocorrer em espaços marcados pelo entendimento mútuo, respeito e responsabilidade; d) a educação em direitos humanos deve estruturar-se na diversidade cultural e ambiental, garantindo a cidadania, o acesso ao ensino, permanência e conclusão, a equidade (étnico-racial, religiosa, cultural, territorial, físico-individual, geracional, de gênero, de orientação sexual, de opção política, de nacionalidade, dentre outras) e a qualidade da educação [...] (BRASIL, 2007, p. 32).

As Diretrizes Nacionais da Educação em Direitos Humanos (DNEDH), publicadas em 2012, têm como objetivo central da EDH a formação para a vida e para a convivência, no exercício cotidiano dos Direitos Humanos (DH) como forma de vida e de organização social, política, econômica e cultural, nos níveis regionais, nacionais e planetário. Assim, as DNEDH recomendam que esse objetivo oriente os sistemas de ensino e suas instituições, no que se refere ao planejamento e ao desenvolvimento de ações de EDH.

Além disso, argumentam que a EDH se fundamenta nos princípios da dignidade humana; da igualdade de direitos, do reconhecimento e da valorização das diferenças e das 
diversidades; da laicidade do Estado; da democracia na educação; da transversalidade, da vivência e da globalidade; e da sustentabilidade socioambiental (BRASIL, 2012, p. 2).

As DNEDH não representam uma fórmula acabada para eliminar as dificuldades da efetivação da EDH. Trazem parâmetros que esclarecem como se deve proceder, permitindo que os trabalhadores em educação, a comunidade escolar e os gestores fiquem livres para adequar as propostas às suas realidades.

A sugestão das Diretrizes não é educar partindo da premissa de que o indivíduo desconhece seus direitos, uma vez que esse indivíduo tem um conhecimento prévio sobre a temática. Pelo contrário, as Diretrizes sugerem uma restauração de valores pelo conhecimento dos direitos humanos. As DNEDH propõem o empoderamento dos sujeitos como aplicação das ações na EDH. Não se trata de uma formação de cunho filantrópico (ajudar por querer ver a pobreza, a discriminação e as desigualdades sanadas), mas de dar à pessoa ferramentas, para que ela própria possa sair dessa situação que impede o seu reconhecimento como pessoa de direito. O empoderamento será a chave-mestra da análise metodológica das Diretrizes Nacionais para a Educação em Direitos Humanos.

\subsection{A Política Pública Educacional e a EDH}

Com vistas a concretizar o que estabelece a Constituição e a LDB, o Plano Nacional de Educação (PNE), que foi aprovado pela Lei n. ${ }^{\circ}$ 13.005/2014 (BRASIL, 2014), com vigência de 10 anos (2014-2024), definiu os objetivos e as metas para o ensino em todos os níveis. São diretrizes do PNE:
Art. $2^{\circ}(\ldots)$
I - erradicação do analfabetismo;
II - universalização do atendimento escolar;
III - superação das desigualdades educacionais, com ênfase na promoção da
cidadania e na erradicação de todas as formas de discriminação;
IV - melhoria da qualidade da educação;
$\mathrm{V}$ - formação para o trabalho e para a cidadania, com ênfase nos valores morais
e éticos em que se fundamenta a sociedade;
VI - promoção do princípio da gestão democrática da educação pública;
VII - promoção humanística, científica, cultural e tecnológica do País;
VIII - estabelecimento de meta de aplicação de recursos públicos em educação
como proporção do Produto Interno Bruto - PIB, que assegure atendimento às necessidades de expansão, com padrão de qualidade e equidade;
IX - valorização dos (as) profissionais da educação;
$\mathrm{X}$ - promoção dos princípios do respeito aos direitos humanos, à diversidade e à sustentabilidade socioambiental (Grifos nossos).

Para atingir essas metas e implementar tais estratégias, a União, os estados, o Distrito Federal e os municípios devem atuar em regime de colaboração, observadas suas competências. Como estratégias relacionadas ao tema DH, o item 4.12 descreve: 
(...) promover a articulação intersetorial entre órgãos e políticas públicas de saúde, assistência social e direitos humanos, em parceria com as famílias, com o fim de desenvolver modelos de atendimento voltados à continuidade do atendimento escolar, na educação de jovens e adultos, das pessoas com deficiência e transtornos globais do desenvolvimento com idade superior à faixa etária de escolarização obrigatória, de forma a assegurar a atenção integral ao longo da vida (Grifos nossos).

A escola como mediadora e propagadora da EDHA, que reforça a necessidade de promoção da democracia, entendida como regime alicerçado na soberania popular, na justiça social e no respeito integral aos direitos humanos, é fundamental para o reconhecimento, a ampliação e a concretização dos direitos. Para o exercício da cidadania democrática, a educação, como direito de todos e dever do Estado e da família, requer a formação dos cidadãos (PNEH).

No Brasil, os Direitos Humanos voltados para a Educação em Direitos Humanos têm como referência o Programa Nacional de Direitos Humanos (PNDH-3), com última versão atualizada em 2010 (BRASIL, 2010), pelo Comitê Nacional de EDH. O Plano Nacional de EDH (PNEDH), de 2007, e as Diretrizes Nacionais para a Educação em Direitos Humanos (DNEDH), de 2012, formam o sistema nacional de EDH. Ou seja, são documentos nacionais que orientam as ações em educação e que devem levar a outros planos ou programas municipais. Esses documentos serão analisados no próximo item.

Isto posto, pergunta-se como a EDH poderia ser incorporada no âmbito dos municípios, por meio de planos específicos ou integrada a outros planos educacionais. Assim, outras políticas educacionais instituídas agregaram diretrizes para a EDH em seu texto: neste trabalho, faz-se importante comentar o Programa Mais Educação (PME) e o Programa Escola Integrada (PEI) que, como será analisado adiante, confirmam que a Educação em Direitos Humanos é um dos Direitos Humanos em constante desenvolvimento.

Os programas, a partir das necessidades locais, especificamente municipais, tiveram que ser adaptados para as escolas de municípios que adotaram a escola Integrada, como no caso de Belo Horizonte. Neste sentido, o artigo destaca a preocupação de como a EDH atingiu outros documentos na esfera da educação.

\subsection{A incorporação da EDH em outros programas nacionais: Programa Mais Educação e Programa Escola Integrada}

Sendo a educação um processo de formação humana, a inserção dos Direitos Humanos nas escolas tornou-se imprescindível. Apesar de jovens, as políticas públicas que regulamentam a educação em Direitos Humanos nunca estiveram distantes do âmbito escolar. Os processos pedagógicos desenvolvidos nas escolas visam à formação integral do ser humano e esses estão, notadamente, vinculados aos Direitos Humanos (BALECHE; 
SILVA, 2017, p. 4). No período estudado, os documentos deixam clara essa preocupação com o direito à educação correlacionado aos direitos humanos e à EDH.

Silva e Tavares (2013, p.53), sintetizam as intenções desta educação: educar em Direitos Humanos potencializa nas pessoas o respeito ao ser humano e à sua dignidade, os valores democráticos, a tolerância e a convivência dentro das regras do estado de direito, sendo capaz de contribuir para que as pessoas assumam o papel de protagonistas de sua história, conscientes de suas responsabilidades sociais, políticas, culturais e artífices das transformações necessárias a cada realidade, (SILVA; TAVARES, 2013, p. 52-53).

Assim, no período estudado, a inserção dos Direitos Humanos na escola, além de constituir-se num direito básico, tem a finalidade de promover a educação para a mudança e a transformação social. Na educação básica, a inserção dos conteúdos de direitos humanos nas escolas devem ser trabalhados em forma de projetos e ações pontuais, articulados com o currículo, conforme diretrizes e programas do Governo.

O Programa Mais Educação (PME) foi criado a partir do Plano de Desenvolvimento da Educação (PDE), instituído pela Portaria Interministerial no 17 de 24 de abril de $2007^{2}$, visando formação integral, conforme os seguintes dispositivos:

Art. $1^{\circ}$ - Instituir o Programa Mais Educação, com o objetivo de contribuir para a formação integral de crianças, adolescentes e jovens, por meio da articulação de ações, de projetos e de programas do Governo Federal e suas contribuições às propostas, visões e práticas curriculares das redes públicas de ensino e das escolas, alterando o ambiente escolar e ampliando a oferta de saberes, métodos, processos e conteúdos educativos.

Parágrafo único - O programa será implementado por meio do apoio à realização, em escolas e outros espaços socioculturais, de ações socioeducativas no contraturno escolar, incluindo os campos da educação, artes, cultura, esporte, lazer, mobilizando-os para a melhoria do desempenho educacional, ao cultivo de relações entre professores, alunos e suas comunidades, à garantia da proteção social da assistência social e à formação para a cidadania, incluindo perspectivas temáticas dos direitos humanos, consciência ambiental, novas tecnologias, comunicação social, saúde e consciência corporal, segurança alimentar e nutricional, convivência e democracia, compartilhamento comunitário e dinâmicas de redes (BRASIL, 2007). (Grifos nossos)

O PME foi uma estratégia do governo federal para induzir a ampliação da jornada escolar e a organização curricular, na perspectiva da educação integral, visando contribuir para a qualificação das aprendizagens escolares, a diminuição das desigualdades educacionais e a valorização da diversidade cultural brasileira (MOLL, 2012 p. 27).

O Programa Mais Educação buscou na intersetorialidade a concretização dessa proposta. A intersetorialidade é concebida pelo programa como a ação conjunta de diferentes políticas públicas, das esferas federal, estaduais e municipais, para atendimento integral das crianças e jovens, envolvendo os diversos ministérios e diferentes iniciativas da sociedade civil, como 
ONGs e empresas, constituindo redes socioeducativas, que devem ser capazes de criar outra cultura de educar-formar, usando as potencialidades educativas da comunidade e da cidade (MOLL, 2012, p.29).

A intenção do programa é não replicar a prática da escolar regular, mas ampliar tempos, espaços e conteúdos, buscando constituir uma educação cidadã, com contribuições de outras áreas sociais e organizações da sociedade civil (BRASIL Secad, 2009, p. 27).

Em 2010, o Decreto n. 7.083 instituiu um novo PME ampliando seus princípios que destacamos a seguir:

Art. 2ำ São princípios da educação integral, no âmbito do Programa Mais Educação:

III - a integração entre as políticas educacionais e sociais, em interlocução com as comunidades escolares;

VI - a afirmação da cultura dos direitos humanos, estruturada na diversidade, na promoção da equidade étnico-racial, religiosa, cultural, territorial, geracional, de gênero, de orientação sexual, de opção política e de nacionalidade, por meio da inserção da temática dos direitos humanos na formação de professores, nos currículos e no desenvolvimento de materiais didáticos; (grifo nosso)

O mesmo Decreto dispõe de vários objetivos para o desenvolvimento do PME, mas destacamos o objetivo $\mathrm{V}$ por se tratar especificamente da educação integral:

O Art. 3ํㅗ̃o objetivos do Programa Mais Educação: [...] V - convergir políticas e programas de saúde, cultura, esporte, direitos humanos, educação ambiental, divulgação científica, enfrentamento da violência contra crianças e adolescentes, integração entre escola e comunidade, para o desenvolvimento do projeto político-pedagógico de educação integral. (Grifo nosso).

Através das esferas estadual e municipal, outros programas para a consolidação do PME foram instituídos para a efetivação da educação integral. Em Belo Horizonte, foi instituído o Programa Escola Integrada (PEI).

\subsection{A EDH e o Programa Escola Integrada no município de Belo Horizonte}

O Programa Escola Integrada (PEI) foi criado em 2006 e entrou em vigência em 2007, através da Secretaria Municipal de Educação, sob a coordenação da Gerência de Educação Integral da Prefeitura de Belo Horizonte. Esse programa foi instituído com o objetivo de contribuir para a melhoria da qualidade da educação, por meio da ampliação da jornada educativa dos estudantes, com ações de formação nas diferentes áreas do conhecimento. 
O PEI visa a formação integral dos sujeitos, indicando o fortalecimento de uma rede de Educação Integral que perpassa pelo trabalho intersetorial, pelo fortalecimento de parcerias, pelo reconhecimento dos saberes da comunidade e, sobretudo, por um trabalho coletivo e contextualizado com todos os atores presentes no cotidiano escolar.

Assim, a articulação dos saberes na elaboração de projetos integradores, ganha força e vitalidade a partir do Projeto Político-Pedagógico, entendido aqui não como um documento formal, mas como instrumento de trabalho que diz da realidade da Escola, suas diretrizes e objetivos (PBH, 2015, p. 13).

É importante nesse contexto que esses projetos integradores tenham como premissa a articulação de saberes e a intencionalidade pedagógica, atuando coletivamente, para o desenvolvimento integral dos estudantes a partir da ampliação da jornada escolar com o consequente aumento da permanência dos estudantes no ambiente da escola.

No caso de Belo Horizonte, esta ampliação se dá não somente nas práticas diárias, mas aos finais de semana e no período das férias. Importa, contudo, a qualificação desse tempo, de modo que as atividades possibilitem aos estudantes novas oportunidades de aprendizagem.

Com a participação das diferentes esferas governamentais, das escolas, de instituições de ensino superior e ONGs, o programa visa garantir nove horas diárias de atendimento educativo para os estudantes, por meio de atividades de acompanhamento pedagógico, cultura, esportes, lazer e formação cidadã, articulando arranjos educativos construídos com base em ações intersetoriais.

O PEI se configura como experiência de ampliação da jornada escolar na Rede de Ensino Municipal de Belo Horizonte e visa o enfrentamento das desigualdades educacionais, proporcionando uma organização, no contraturno, em forma de oficinas, utilizando diferentes recursos didáticos e culturais, como artes, dança, brincadeiras, contação de histórias, jogos e outros. Também eram utilizados espaços externos à escola, como parques e clubes, mostrando uma concepção extramuros próxima à comunidade.

A proposta pedagógica do Programa Escola Integrada permite a inserção nos espaços não escolares e escolares, proporcionando a exploração, o conhecimento, a apropriação e a intervenção para que os estudantes e demais sujeitos construam novas condições de participação, relações pessoais e de pertencimento.

Como parte do desenvolvimento integral dos estudantes, entende-se a formação em direitos humanos e, neste sentido, a EDH na escola integral compreende um conjunto de atividades educacionais que tem a finalidade de promover o respeito dos direitos e liberdades fundamentais, contribuindo para a prevenção e combate ao preconceito, discriminação e violências. Essas atividades devem proporcionar conhecimento, habilidades, competências e empoderamento para que os estudantes sejam protagonistas da construção e promoção de uma cultura de direitos humanos. Segundo o Manual Operacional de Educação Integral (2012, p. 9), a EDH se dará:

Por meio de múltiplas linguagens artísticas, entre as quais a fotografia, o vídeo, a literatura, a música e a dança, esta atividade se propõe a abordar os direitos humanos de maneira transversal e interdisciplinar, levando os estudantes a 
refletirem e dialogarem sobre seus direitos e responsabilidades enquanto protagonistas de uma sociedade livre, pluralista e inclusiva, a partir do contexto escolar e social no qual estão inseridos. Os recursos disponibilizados permitem que ao longo do ano sejam organizadas exibições fotográficas, apresentações musicais e teatrais, mostra de vídeos, entre outros, a respeito das diversas temáticas de direitos humanos, quais sejam: proteção da infância e adolescência; equidade de gênero e diversidade sexual; enfrentamento ao trabalho infantil; bullying; memória e verdade; história e cultura africana e indígena; inclusão de pessoas com deficiência; democracia e cidadania; liberdade artística, livre expressão do pensamento, entre outras.

Nas Diretrizes Político-Pedagógicas e Operacionais do PEI, a EDH:

Abrange um conjunto de atividades educacionais que têm a finalidade de promover o respeito dos direitos e liberdades fundamentais, contribuindo para a prevenção e o combate ao preconceito, à discriminação e à violência. As atividades devem proporcionar aos educandos conhecimento, habilidades, competências e empoderamento, para que sejam protagonistas da construção e promoção de uma cultura de direitos humanos (BRASIL, 2014, p. 33).

O acompanhamento pedagógico como meio da EI visa as oportunidades de aprendizado dos alunos beneficiados, de modo a favorecer a construção de valores sociais, de conhecimentos e atitudes voltadas para a conquista da sustentabilidade socioambiental. Busca desenvolver ações baseadas em práticas corporais lúdicas e esportivas que enfatizam a presença da cultura local e o fortalecimento da diversidade cultural, bem como uma educação em direitos humanos que visa promover o respeito aos direitos e a liberdade, com vistas a contribuir para a prevenção e o combate ao preconceito, à discriminação e à violência.

Para efetivação da EDH o envolvimento da comunidade é importante. Mas este envolvimento ocorre também em outros espaços para a prática educativa, ligando a escola com a vida da comunidade, considerando os saberes emanados do contexto local para, através do envolvimento e participação, dividir com a comunidade e com as demais instituições a responsabilidade sobre a educação. Tal ação amplia o conceito de "território educativo", visto como um lugar de vida, de relações, e remete a uma concepção mais abrangente de educação, em que o processo educativo confunde-se com um processo amplo e multiforme de socialização. Logo, a formação dos sujeitos da educação é considerada inseparável das relações e transformações ocorridas no ambiente, a partir do entendimento do caráter territorial dos processos educacionais na escola e na cidade (SILVA, 2013, p. 84).

Portanto, educar em Direitos Humanos a partir de uma proposta de Educação Integral, requer, segundo a educadora Jaqueline Moll (2009, p. 15), que:

[...] pensemos na aproximação das práticas escolares em relação às outras práticas sociais e culturais, aos espaços urbanos tratados como territórios educativos. Pensemos ainda na escola em meio a um processo que implica saberes escolares aos saberes que "circulam" nas praças, nos parques, nos museus, nos teatros, nos 
cinemas, nos clubes, nos espaços de inclusão digital, nos movimentos em favor dos direitos humanos materializados na proteção das mulheres, das crianças e dos jovens.

Como contributo para o desenvolvimento humano, num contexto de educação pública e democrática, deve-se considerar os múltiplos saberes existentes nos diferentes atores sociais (poder público, comunidade escolar e sociedade civil) numa construção permanente de um projeto educativo que respeite e promova os direitos humanos e o exercício da democracia.

A Educação Integral necessita estabelecer vínculos com a EDH realizada nas escolas, devendo inspirar e instigar a promoção e a afirmação dos direitos humanos no cotidiano do contexto escolar, como uma possibilidade de encurtar e minimizar as distâncias e desigualdades culturais, sociais, políticas e econômicas existentes em nossa sociedade, bem como oportunizar a apropriação de saberes sobre a noção de direitos que viabilizem e fortaleçam laços de convivência dos educandos, tendo presente o respeito à diversidade e à pluralidade com relação aos jeitos diferentes de ser e de conviver.

Nos diversos documentos, a EDH na Educação Integral prevê um processo formativo composto por escola, família e comunidade e configura-se como ferramenta de articulação entre o bairro, o processo educativo escolar e a participação da comunidade, com ações em diversas áreas de conhecimento, como cultura, esporte, lazer, direitos humanos, meio ambiente e desenvolvimento social (BRASIL, 2014, p. 21).

Em Belo Horizonte, o Plano de Educação Integral (PEI) foi instituído em todas as escolas da rede e a EDH é tratada nas mais diversas atividades que ocorrem no contraturno escolar e contribuem efetivamente no desenvolvimento pessoal, social, moral e cultural dos seus alunos.

Pelo programa, a EDH na Escola Integrada deve dialogar com conhecimentos, equipamentos e serviços disponíveis na comunidade. Os estudantes percorrem o bairro, a cidade, praticam esportes, participam de competições e torneios, visitam museus, salas de cinemas, teatros e têm acesso a diferentes manifestações esportivas, culturais e de lazer oferecidas pela cidade.

O programa pressupõe, ainda, a articulação de ações intersetoriais entre diferentes esferas governamentais, com a incorporação das boas práticas educacionais e sociais existentes em Belo Horizonte (PBH).

\section{Considerações Finais}

Educação em Direitos Humanos é a formação para os Direitos Humanos, ou seja, para a participação ativa na sociedade democrática, na vida pública de nossa sociedade com a consideração dos alunos como sujeitos de direitos.

Neste artigo, procurou-se compreender como o Programa Escola Integrada, em Belo Horizonte, se apropriou e expressou os objetivos da EDH, em nível local. Nesse sentido, pode-se afirmar que a Educação Integral é fruto de debates entre o poder público, a 
comunidade escolar e a sociedade civil, de forma a assegurar o compromisso coletivo com a construção de um projeto de educação que estimule o respeito aos direitos humanos e o exercício da democracia.

Em relação aos conteúdos relativos à EDH (que, no PNEDH, poderiam ser dados por meio de atividades, interações e outros recursos didáticos), a Educação Integral, em Belo Horizonte, reconheceu crianças e os jovens como sujeitos de direito ${ }^{3}$, podendo participar e criar na interação com os seus pares, com a comunidade escolar.

Nesse sentido, atribuiu importância ao desenvolvimento de atividades que pudessem promover o respeito aos direitos, trabalhando com os alunos, por meio de oficinas e outras atividades pedagógicas, a construção de valores sociais, conhecimentos e atitudes, incluindo o combate ao preconceito e à violência, por meio de diversos recursos pedagógicos, diferentes linguagens e utilização de espaços intra e extramuros (Manual Operacional de Educação Integral, 2012).

Um outro ponto é que, na Escola Integrada, a relação com a comunidade se mostrou importante:

(...) não passa apenas pela possibilidade de deslocamento das atividades de dentro da escola para fora da escola. Sair da escola não significa simplesmente aprender os conteúdos curriculares em outro lugar, com uma aparência mais atrativa e moderna - significa ir além e abrir possibilidades concretas para que os assuntos que interessam às crianças e aos jovens e aqueles assuntos que preocupam a comunidade sejam objeto do trabalho sistemático da escola (BRASIL, 2011, p. 21).

Conforme argumenta o Centro de Estudos e Pesquisa em Educação, Cultura e Ação Comunitária (CENPEC):

A escola só estará compreendendo o aluno com o qual lida e o espaço em que ele vive, se intensificar a sua prática na vida do território, nele se enraizando. Cabe a ela representar a cultura local, valorizá-la, disseminá-la propiciando o intercâmbio entre ela e o que é disposto no mundo, para melhorar a vida do sujeito e de sua comunidade. A educação integral acolhe e coloca em contato diferentes saberes, diferentes manifestações culturais e diferentes óticas. A contemporaneidade requer culturas que se misturem e se influenciem mutuamente, que convivam e se modifiquem num processo contínuo (CENPEC, 2011, p.54).

Segundo Dowbor (2006) a geração de conhecimentos sobre a realidade local e a promoção de uma atitude proativa para o desenvolvimento fazem parte evidente de uma educação que pode se tornar no instrumento científico e pedagógico da transformação local. Assim, a proposta da Educação Integral incorpora a concepção de que os cidadãos devem conhecer e se apropriar de sua realidade local, como pressuposto para o desenvolvimento de sua cidadania. Como afirma Dowbor: 
A ideia da educação para o desenvolvimento local está diretamente vinculada a essa compreensão e à necessidade de se formarem pessoas que amanhã possam participar de forma ativa das iniciativas capazes de transformar o seu entorno, de gerar dinâmicas construtivas. Hoje, quando se tenta promover iniciativas desse tipo, constata-se que não só as crianças, mas mesmo os adultos desconhecem desde a origem do nome da sua própria rua até os potenciais do subsolo da região onde se criaram. Para termos cidadania ativa, temos de ter uma cidadania informada, e isso começa cedo. A educação não deve servir apenas como trampolim para uma pessoa escapar da sua região: deve dar-lhe os conhecimentos necessários para ajudar a transformá-la (DOWBOR, 2006, p.1).

Na Escola Integral, a EDH se mostra indissociável com a educação, sendo a escola um cenário para esse constante debate, além de proteger e promover os direitos humanos. A escola pode e deve promover os direitos humanos em suas práticas e vivência cotidianas, envolvendo os sujeitos, desenvolvendo e transformando de forma integrada e integral. Nesse sentido:

[...] não é possível dissociar a questão das estratégias metodológicas para a educação em Direitos Humanos de uma visão político-filosófica, de uma concepção dos direitos humanos e do sentido de se educar em Direitos Humanos numa determinada sociedade em um momento histórico concreto (CANDAU, 2008, p. 291).

Para a sua expressão em uma realidade local, a EDH precisa ser incorporada a políticas públicas, no caso, a educação municipal, incluindo programas específicos como foi o caso da Escola Integrada. Como disse Mahoney (2002), a escola reúne diversidades que dizem respeito ao conhecimento, mas, também, a outras diferenças de valores e modos de vida que se expressam em nível local. Na concepção e implementação das políticas públicas, é importante que, conforme Dessen e Polônia (2007), seja assegurada a aproximação entre os contextos, reconhecendo as suas similaridades e diferenças.

A educação é um pilar da sociedade e a EDH é uma acepção capaz de dar sentido à formação dos indivíduos, sujeitos de direitos e garantias fundamentais, cujo envolvimento e participação podem provocar melhorias para o bem-estar social e o desenvolvimento local e proteção contra violação dos Direitos humanos. Nesta pesquisa, constatou-se que a EDH foi associada de maneira específica ao Programa Escola Integrada, em Belo Horizonte.

Assim, embora a presente pesquisa tenha, como limitação, o foco apenas na análise documental, é possível identificar que a Educação em Direitos Humanos a partir do Programa da Escola Integrada auxilia na formação e desenvolvimento das crianças e adolescentes, bem como na transformação local pela participação colaborativa da sociedade.

Espera-se que a presente pesquisa possa contribuir para a discussão dos processos que existem entre os planos nacionais e os projetos municipais. A compreensão da sintonia - ou da disparidade - entre os documentos de âmbito nacional e os municipais pode colaborar para orientar a implementação da EDH nas escolas, nos diversos municípios brasileiros, de 
realidade tão diversa. Outrossim, serve também como testemunho de uma proposta educativa, a Escola Integrada, que visa à cidadania e que agrega sentidos novos à educação no Brasil, ainda que, na prática, muitas sejam - e venham a ser - as dificuldades para a sua real implementação.

\section{Notas}

1. Artigo derivado da dissertação de "Análise das diretrizes da educação em direitos humanos do ensino fundamental da escola integrada em Belo Horizonte", orientada pela Professora Doutora Maria Lucia Miranda Afonso, defendida em 24 de outubro de 2019 no PPG Gestão Social, Educação e Desenvolvimento Local do Centro Universitário UNA.

2. É importante enfatizar que este estudo abordou os citados Programas até o ano de 2018, não sendo possível fazer projeções para o período posterior, que introduziu mudanças de gestão.

3. Sujeitos de Direitos: a Educação Integral reconhece as crianças e os jovens como sujeitos de direito, atores sociais com expressão e linguagens singulares. São criadores e produtores de culturas próprias construídas na interação com seus próprios pares e no intercâmbio entre idades e gerações. Propostas de Educação Integral oportunizam tempo e espaço para a livre criação de suas culturas e valorizam e reconhecem saberes, fazeres e sentimentos expressados por meio do universo simbólico e artístico. Disponível em: <http://educacaointegral.org.br/conceito/>. Acesso em: 27 jul. 2018.

\section{Referências}

AFONSO, Maria Lúcia Miranda; ABADE, Flávia Lemos. Jogos para pensar: educação em direitos humanos e formação para a cidadania. Belo Horizonte: Autêntica, 2013.

ARAUJO, Aline Soares Storch de; AFONSO, Maria Lúcia Miranda Afonso. A educação em direitos humanos na educação infantil: formação de sujeitos de direitos. Revista Eletrônica de Educação, v. 12, n. 1, p. 46-60, jan./abr. $2018 . \quad$ Disponível em: <http://www.reveduc.ufscar.br/index.php/reveduc/article/viewFile/1887/667>. Acesso em: 27 out. 2020.

BARCELOS, Luciano Henrique; AFONSO, Maria Lúcia Miranda. Gestão Social da (in)disciplina na escola e a educação para a cidadania. Educação por Escrito, Porto Alegre, v. 6, n. 1, p. 98-117, jan/jun. 2015.

ANDRADE, Marcelo. Educação como direito humano e a formação de educadores/as em direitos humanos. In: CANDAU, Vera Maria; SACAVINO, Suzana. Educação em direitos humanos: temas, questões e propostas. Petrópolis: Editora DP, 2008.

BENEVIDES, Maria Victória. Cidadania e direitos humanos. In: CARVALHO, José Sérgio (Org.). Educação, Cidadania, Direitos Humanos. Petrópolis: Vozes, 2004.p 43-65

BRASIL. Lei $\mathbf{n}^{\mathbf{0}}$. 9.394, de 20 de dezembro de 1996. Estabelece as Diretrizes e Bases da Educação Nacional. Brasília.

BRASIL. Secretaria Especial dos Direitos Humanos/Ministério da Educação. Comitê Nacional de Educação em Direitos Humanos. Plano Nacional de Educação em Direitos Humanos. Brasília, 2007.

BRASIL. Ministério da Educação. Secretaria de Educação Continuada, Alfabetização e Diversidade. Série Mais Educação. Programa Mais Educação: Gestão intersetorial no território. Brasília: MEC. 2009.

BRASIL. MINISTÉRIO DA EDUCAÇÃO. Secretaria de Educação Continuada, Alfabetização e Diversidade do Ministério da Educação. Série Mais Educação. Educação integral: texto referência para o debate nacional. Brasília: Mec, $\quad$ Secad, $2009 . \quad$ Disponível $\quad$ em http://portal.mec.gov.br/dmdocuments/cadfinal_educ_integral.pdf. Acesso em 23 mar. 2018. 
BRASIL. Direitos Humanos em Educação. Cadernos Pedagógicos do Programa Mais Educação, 2009. Disponível em: 〈http://educacaointegral.mec.gov.br/images/pdf/pme/direitos_humanos.pdf〉. Acesso em: 23 mar. 2018.

BRASIL. Programa Nacional de Direitos Humanos (PNDH-3). Secretaria Especial dos Direitos Humanos da Presidência da República. Brasília: SEDH/PR, 2010.

BRASIL. MINISTÉRIO DA EDUCAÇÃO. Secretaria de Educação Básica. Série Mais Educação. Caminhos para elaborar uma proposta de Educação Integral em Jornada Ampliada. Brasília. 2011. Disponível http://portal.mec.gov.br/index.php?option=com_docman\&view=download\&alias=8194-4-caminhoselaborar-educacao-integral-cecipe-seb-pdf\&category_slug=junho-2011-pdf\&Itemid=30192. Acesso em: 23 mar. 2018.

BRASIL. MINISTÉRIO DA EDUCAÇÃO Secretaria de Educação Básica Diretoria de Currículos e Educação Integral. Manual Operacional de Educação Integral Brasília/DF 2012.

BRASIL. Ministério da Educação. Resolução CNE/CP n. 1, de 30 de maio de 2012. Estabelece as Diretrizes Nacionais para a Educação em Direitos Humanos. Brasília, DF: 2012.

BRASIL. Secretaria de Direitos Humanos da Presidência da República. Educação em Direitos Humanos: Diretrizes Nacionais. Brasília: Coordenação Geral de Educação em SDH/PR, Direitos Humanos, Secretaria Nacional de Promoção e Defesa dos Direitos Humanos, 2013.

BRASIL. MINISTÉRIO DA EDUCAÇÃO. Secretaria da Educação Básica. Diretoria de Currículos e Educação Integral. Manual Operacional de Educação Integral. Brasília, 2013. Disponível em: $<$ http://portal.mec.gov.br/index.php?option=com_docman\&view=download\&alias=14458-manual-maiseducacao-2013-final-171013-2-pdf\&Itemid=30192>. Acesso em: 23 mar. 2018.

BRASIL. Ministério da Educação. Plano Nacional de Educação. Brasília, 2014.

CANDAU, Vera (org.). Magistério: construção cotidiana. Petrópolis, Rio de Janeiro: Vozes, 1997. p. 51-68.

CANDAU, Vera Maria Ferrão FERNANDES, Yrama Siqueira. Direito à qualidade da educação e educação em direitos humanos: inter-relações e desafios. Educação (Porto Alegre), v. 40, n. 1, p. 2-9, jan.-abr. 2017.

CANDAU, Vera. Educação em Direitos Humanos. Revista Novamérica, Rio de Janeiro, n. 78, 1998.

CANDAU, Vera. Educação em direitos humanos: uma proposta de trabalho. In: ZENAIDE, Maria de Nazaré. (Org.). Oficinas aprendendo e ensinando direitos humanos. João Pessoa: JB Ed., 1999. p. 13-25.

CANDAU, Vera. Educação em direitos humanos: desafios atuais. In: R. M. G. Silveira, A. A. Dias, L. F. G. Ferreira, M. L. P. A. M. Feitosa, \& M. N. T. Zenaide (Org.). Educação em direitos humanos: fundamentos teórico-metodológicos. João Pessoa: Editora Universitária, 2007, p.399-412.

CANDAU, Vera. Direitos Humanos, educação e interculturalidade: as tensões entre igualdade e diferença. Revista Brasileira de Educação, v. 13, n. 37, p. 45-56, jan./abr. 2008.

CANDAU, Vera. Direito à educação, diversidade e educação em direitos humanos. Revista Educação Social, Campinas, v. 33, n. 120, p. 715-726, jul./set. 2012.

CANDAU, Vera Maria Ferrão; SACAVINO, Susana Beatriz.Educação em direitos humanos e formação de educadores. Educação (Porto Alegre, impresso), v. 36, n. 1, p. 59-66, jan./abr. 2013

CENTRO DE ESTUDOS E PESQUISA EM EDUCAÇÃO, CULTURA E AÇÃO COMUNITÁRIA (CENPEC). Tendências para a educação integral. São Paulo: Fundação Itaú Social, 2011. Disponível em: <https://www.unicef.org/brazil/pt/br_tend_educ_integ.pdf>. Acesso em: 23 mar., 2018.

CENTRO DE REFERÊNCIA DA ESCOLA INTEGRADA. https://educacaointegral.org.br/experiencias/ gestao-publica-criou-programa-verdadeiramente-intersetorial/ Acesso em: 29 set. 2020

COSTA, Alline Grazielle Neves; NOVAIS, Gercina Santana. Educação em direitos humanos, formação de professores e educação popular. IDEA Revista, v. 3, n. 1, ago./set. 2011. 
DESSEN, Maria Auxiliadora; POLONIA; Ana da Costa. Família e a Escola como contextos de desenvolvimento humano. Disponível em: 〈http://www.scielo.br/pdf/paideia/v17n36/v17n36a03.pdf>. Acesso em: 23 mar. 2018.

DOWBOR, L. Educação e desenvolvimento local. 2006. Disponível em: 〈http://dowbor.org〉. Acesso em: 29 out. 2017.

FERNANDES, Yrama Siqueira; CANDAU, Vera Maria Ferrão. Direito à qualidade da educação e educação em direitos humanos: inter-relações e desafios. Revista Educação, Porto Alegre, v. 40, n. 1, p. 2-9, jan./abr. 2017.

LAFER, Celso. A reconstrução dos direitos humanos: a contribuição de Hannah Arendt. Estudos Avançados. São Paulo, vol. 11, n. 30, p.55-65, 1997.

MAHONEY, A. A. Contribuições de Henri Wallon para a reflexão sobre questões educacionais. Psicologia da Educação, EDUC, v. 1, n.7/8, p. 9-28, 1999.

MOLL, Jaqueline. Um paradigma contemporâneo para a educação integral. Pátio - Revista Pedagógica. Porto Alegre: Artmed, v. 13, ago./out 2009.

MOLL, J. et al. Caminhos da educação integral no Brasil: direito a outros tempos e espaços educativos. Porto Alegre: Penso, 2012.

ORGANIZAÇÃO DAS NAÇÕES UNIDAS (ONU). Declaração Universal dos Direitos Humanos. Paris: ONU, 1948.

ORGANIZAÇÃO DAS NAÇÕES UNIDAS PARA EDUCAÇÃO, CIÊNCIA E CULTURA (UNESCO). Programa Mundial de Educação em Direitos Humanos: Plano de Ação. New York e Genebra, 2006. Disponível em: <http://www.dhnet.org.br/dados/textos/edh/br/plano_acao_programa_mundial_edh_ pt.pdf>. Acesso em: 19 jul 2018.

PIOVESAN, Flavia. Direitos sociais, econômicos e culturais e direitos civis e políticos. Sur, Revista Internacional de Direitos Humanos. 2004, v.1, n.1, p. 20-47. ISSN 1983-3342. Disponível em: < http://www.scielo.br/pdf/sur/v1n1/a03v1n1.pdf>. Acesso em: 23 mar. 2018.

PREFEITURA DE BELO HORIZONTE. Escola Integrada. Disponível em: <https://prefeitura.pbh.gov.br/educacao/escola-integrada>. Acesso em: 15 set. 2020

PREFEITURA DE BELO HORIZONTE (PBH). Secretaria Municipal de Belo Horizonte. Projeto Político Pedagógico Projeto Escola Integrada. Belo Horizonte, 2006/2007.

SACAVINO, Susana. Educação em Direitos Humanos e Democracia. In: CANDAU, Vera; SACAVINO, Susana. Educar em Direitos Humanos. Rio de Janeiro: D\&P Editora, 2000, p. 36-48.

SCHIEFER, Uyára. Sobre os direitos fundamentais da pessoa humana. 2004. Disponível em https://www.revistapersona.com.ar/Persona28/28Schiefer.htm Acesso em: 15 set 2020.

SILVA, A.M.M.; TAVARES C. Educação em direitos humanos no Brasil: contexto, processo de desenvolvimento, conquistas e limites. Revistas eletrônicas PUCRS - Educação, Porto Alegre, v. 36, n. 1, p. 50-58, jan./abr. 2013.

SILVA, Ana Maria Clementino Jesus. Trabalho docente e educação em tempo integral: um estudo sobre o programa escola integrada e o projeto educação em tempo integral. 2013. 186 f. Dissertação de Mestrado em Políticas Públicas de Educação: Concepção, Implementação e Avaliação - Faculdade de Educação, Universidade Federal de Minas Gerais, Belo Horizonte, 2013. Disponível em: http://www.bibliotecadigital.ufmg.br/dspace/bitstream/handle/1843/BUBD-9HMGL W/dissertacao_final_ana_clementino.pdf?sequence=1>. Acesso em: 23 mar. 2018.

TENÓRIO, Fernando Guilherme (Org.). Cidadania e desenvolvimento local. Rio de Janeiro: FGV; Ijuí: Ed. Unijuí, 2007. 
TAVARES, Celma. Educar em direitos humanos: o desafio da formação dos educadores numa perspectiva interdisciplinar. In: SILVEIRA, Rosa Maria Godoy, et. al. (org.). Educação em direitos humanos: fundamentos teórico-metodológicos. João Pessoa: UFPB, 2007, p. 487-503.

\section{Correspondência:}

Patrícia dos Santos Dias Viana: Advogada, Procuradora Institucional e Secretária Acadêmica da Faculdade SKEMA Business School, Mestre em Gestão Social, Educação e Desenvolvimento Local pelo Centro Universitário UNA.

E-mail: patriciasdv.adv@gmail.com

Maria Lúcia Miranda Afonso: Psicóloga, Mestre e Doutora em Educação, Docente no Programa de Pósgraduação Stricto Sensu do Centro Universitário UNA.

E-mail: luafonso@yahoo.com

Texto publicado em Currículo sem Fronteiras com autorização das autoras 